\title{
Oral cancer screening programmes
}

\author{
Abstracted from \\ Brocklehurst P, Kujan O, Glenny AM, Oliver R, Sloan P, Ogden G, Shepherd S. \\ Screening programmes for the early detection and prevention of oral cancer. \\ Cochrane Database of Systematic Reviews 2010, Issue 11. \\ Address for correspondence: Luisa Fernandez Mauleffinch, Review Group Co-ordinator, \\ Cochrane Oral Health Group, MANDEC, School of Dentistry, University of Manchester, \\ Higher Cambridge Street, Manchester M15 6FH, UK. E-mail: luisa.fernandez@manchester.ac.uk
}

\section{Question: Are current screening methods effective in reducing cancer mortality?}

Data sources The Cochrane Oral Health Group Trials Register, the Cochrane Central Register of Controlled Trials (CENTRAL), Medline, Embase and CANCERLIT.

Study selection Randomised controlled trials (RCTs) of screening for oral cancer or potentially malignant disorders using visual examination, toluidine blue, fluorescence imaging or brush biopsy were included. There were no restrictions regarding language or date of publication. Data extraction and synthesis The original review identified 1,389 citations and this update identified an additional 330 studies. Validity assessment, data extraction and statistics evaluation were undertaken by six independent review authors.

Results Only one 9-year cluster RCT was included ( $n=13$ clusters: 191,873 participants). No statistically significant differences in the age-standardised oral cancer mortality rates for the screened group (16.4/100,000 person-years) and the control group (20.7/100,000 person-years) were identified. A $43 \%$ reduction in mortality was reported between the intervention cohort (29.9/100,000 person-years) and the control arm $(45.4 / 100,000)$ for high-risk individuals who used tobacco or alcohol or both, which was statistically significant. However, this study had a number of methodological weaknesses and the associated risk of bias was high.

Conclusions Although there is evidence that a visual examination as part of a population-based screening programme reduced the mortality rate of oral cancer in high-risk individuals, whilst producing a stage shift and improvement in survival rates across the population as a whole, the evidence is limited to one study and is associated with a high risk of bias. This was compounded by the fact that the effect of cluster randomisation was not accounted for in the analysis. Furthermore, no robust evidence was identified to support the use of other adjunctive technologies like toluidine blue, brush biopsy or fluorescence imaging within a primary care environment. Further RCTs are recommended to assess the efficacy, effectiveness and cost-effectiveness of a visual examination as part of a population based screening programme.

This paper is based on a Cochrane Review published in the Cochrane Library 2010, issue 2 (see www.thecochranelibrary.com for information). Cochrane Reviews are regularly updated as new evidence emerges and in response to feedback, and the Cochrane Library should be consulted for the most recent version of the review.

\section{Commentary}

This review updates the original which we first saw in $2004^{1}$ and follows the standard Cochrane methodologically approach which includes regular updating. However, while 330 new studies were considered, none met the criteria for inclusion. As a result the review again focuses on the Trivandrum Oral Cancer Screening Study, in Kerala, India.

Recently another trial of oral cancer screening in Taiwan has been published $^{2}$ (see page 104). However, we are yet to see data from trials in Western or low prevalence populations. This is important to consider when the conclusions of the review are examined. For, while there was evidence that a visual examination as part of a population-based screening programme reduced the mortality rate of oral cancer in highrisk individuals and there was both a stage shift and improvement in survival rates across the population, there is only this single study with a high risk of bias in a population with a high incidence of oral cancer.

Speight et $a l^{3}$ in a modelling study of oral cancer screening in general dental practice suggested that oral examination of highrisk individuals may be a cost effective screening strategy. In the UK the National Screening Committee (www.screening.nhs.uk/ oralcancer) recently decided that oral cancer screening should not be offered. Oral cancer remains a significant, and in some areas a growing public health problem and dentists have a duty to play their part in mitigating this problem. However at this time as this review finds, 'there is not enough evidence to decide whether screening by visual inspection reduces the death rate for oral cancer, and there is no evidence for other screening methods'. Until that evidence is forthcoming dentists can play their part by remaining alert for signs of potentially malignant lesions or early-stage cancers in all patients while performing routine visual and tactile examinations, particularly for patients who use tobacco or who are heavy consumers of alcohol as recommended in the recent clinical recommendations from the American Dental Association. ${ }^{4}$ In additional they should encourage they patients to stop using tobacco and betel quid and keep alcohol use to within recommended minimum levels.

Derek Richards

Centre for Evidence-based Dentistry, Oxford.

1. Allison P. Effectiveness of screening for oral cancer not proven. Evid Based Dent 2004; 5: 40-41.

2. Su WW, Yen AM, Chiu SY, Chen TH. A community-based RCT for oral cancer screening with toluidine blue. J Dent Res 2010; 89: 933-937.

3. Speight PM, Palmer S, Moles DR, Downer MC, Smith DH, Henriksson M, et al. The costeffectiveness of screening for oral cancer in primary care. Health Technol Assess 2006; 10: $1-144$.

4. Rethman MP, Carpenter W, Cohen EE, Epstein J, Evans CA, Flaitz CM, et al; American Dental Association Council on Scientific Affairs Expert Panel on Screening for Oral Squamous Cell Carcinomas. Evidence-based clinical recommendations regarding screening for oral squamous cell carcinomas. / Am Dent Assoc 2010; 14: 509-520.

Evidence-Based Dentistry (2010) 11, 103. doi:10.1038/sj.ebd.6400751 